\title{
Seed Priming Alters the Production and Detoxification of Reactive Oxygen Intermediates in Rice Seedlings Grown under Sub-optimal Temperature and Nutrient Supply
}

\author{
Saddam Hussain ${ }^{1}$, Fahad Khan', Weidong $\mathrm{Cao}^{2}$, Lishu Wu${ }^{1}$ and Mingjian Geng ${ }^{1 *}$ \\ ${ }^{1}$ College of Resources and Environment, Huazhong Agricultural University, Wuhan, China, ${ }^{2}$ Institute of Agricultural \\ Resources and Regional Planning, Chinese Academy of Agricultural Sciences, Beijing, China
}

\section{OPEN ACCESS}

Edited by:

Shabir Hussain Wani,

Sher-e-Kashmir University

of Agricultural Sciences

and Technology of Kashmir, India

Reviewed by:

Faroog Shah

Abdul Wali Khan University Mardan,

Pakistan

Wajid Nasim

Commonwealth Scientific

and Industrial Research Organisation,

Australia

Bozena Sera,

South Bohemia University, Czech

Republic

*Correspondence:

Mingjian Geng

mjgeng@mail.hzau.edu.cn

Specialty section:

This article was submitted to Crop Science and Horticulture,

a section of the journal

Frontiers in Plant Science

Received: 01 February 2016

Accepted: 21 March 2016

Published: 05 April 2016

Citation:

Hussain S, Khan F, Cao W, Wu L and Geng M (2016) Seed Priming

Alters the Production and Detoxification of Reactive Oxygen Intermediates in Rice Seedlings Grown under Sub-optimal

Temperature and Nutrient Supply.

Front. Plant Sci. 7:439.

doi: 10.3389/fpls.2016.00439
The production and detoxification of reactive oxygen intermediates (ROIs) play an important role in the plant response to nutrient and environmental stresses. The present study demonstrated the behavior of growth, ROls-production and their detoxification in primed and non-primed rice seedlings under chilling stress $\left(18^{\circ} \mathrm{C}\right)$ and nitrogen-(N), phosphorus-(P), or potassium-(K) deprivation. The results revealed that chilling stress as well as deprivation of any mineral nutrient severely hampered the seedling growth of rice, however, seed priming treatments (particularly selenium- or salicylic acid-priming), were effective in enhancing the rice growth under stress conditions. The $\mathrm{N}$-deprivation caused the maximum reduction in shoot growth, while the root growth was only decreased by $\mathrm{P}$ - or K-deprivation. Although, $\mathrm{N}$-deprivation enhanced the root length of rice, the root fresh weight was unaffected. Rate of lipid peroxidation as well as the production of ROls, was generally increased under stress conditions; the K-deprived seedlings recorded significantly lower production of ROls than $\mathrm{N}$ - or P-deprived seedlings. The responses of enzymatic and non-enzymatic antioxidants in rice seedlings to chilling stress were variable with nutrient management regime. All the seed priming were found to trigger or at least maintain the antioxidant defense system of rice seedlings. Notably, the levels of ROls were significantly reduced by seed priming treatments, which were concomitant with the activities of ROls-producing enzymes (monoamine oxidase and xanthine oxidase), under all studied conditions. Based on these findings, we put forward the hypothesis that along with role of ROls-scavenging enzymes, the greater tolerance of primed rice seedlings can also be due to the reduced activity of ROls-producing enzymes.

\footnotetext{
Keywords: antioxidant defense system, chilling stress, monoamine oxidase, nutrient deprivation, reactive oxygen intermediates, seed priming
}

\section{INTRODUCTION}

Rice, a staple food for more than half of the world's population, possesses an odd portfolio of tolerance and susceptibility to abiotic stresses compared with other crops. Rice belongs to tropical and subtropical environments and is extremely sensitive to low temperature particularly during early growth stages (Yoshida, 1981). Moreover, rice growth and development is controlled by 
optimum supply of nutrients like nitrogen $(\mathrm{N})$, phosphorus $(\mathrm{P})$, and potassium $(\mathrm{K})$, and the suboptimal levels of these nutrients is the key limiting factor of rice production throughout the world (Marschner, 1986). Nitrogen is an important component of amino acids and proteins, and it regulates the enzyme activities that are required for energy metabolism including photosynthesis and respiration (Marschner, 1986; De Groot et al., 2003; Epstein and Bloom, 2005). Phosphorus is the constituent of key cellular molecules (such as ATP, nucleic acids, and phospholipids) and has a pivotal role in energy conservation and metabolism (De Groot et al., 2003; Chevalier and Rossignol, 2011; Deng et al., 2014). Likewise, K supply is inevitable for optimum plant growth and development, and it plays important role in plant cellular homeostasis by contributing to osmotic adjustment, charge balance and enzyme catalysis (Marschner, 1986; Epstein and Bloom, 2005; Deng et al., 2014).

The effects of abiotic stresses at whole plant level are usually perceived as a decrease in growth associated with alteration in carbon and $\mathrm{N}$ metabolism (Law et al., 2001), and oxidative damage by increased production of reactive oxygen intermediates (ROIs) such as the superoxide radical, hydrogen peroxide, singlet oxygen, and hydroxyl radicals (Mittler, 2002; Gill and Tuteja, 2010). Under optimum growing conditions, plants generally maintain a delicate balance between production and scavenging of ROIs. However, such equilibrium may be perturbed by exposure to stress conditions such as chilling and nutrient deprivation, leading to a sudden increase in intracellular levels of ROIs (Foyer and Noctor, 2003). It has been estimated that $1-2 \%$ of oxygen consumption under stress conditions leads to the generation of ROIs in plant tissues (Bhattachrjee, 2005). The production of ROIs occurs from different pathways such as photorespiration, photosynthesis, and mitochondrial respiration. However, it has also been reported that environmental stresses trigger the active production of ROIs by monoamine oxidase (MAO), xanthine oxidase (XOD), and NADPH oxidases (Mittler, 2002). The enhanced ROIsproduction under stress negatively affects the cellular and metabolic functions of the plants by damaging the nucleic acids, proteins, lipids, and carbohydrates, and causing lipid peroxidation (Gill and Tuteja, 2010). The perturbation of chloroplastic and mitochondrial metabolism under excessive ROIs-generations also leads to reduced respiration rate and energy supply for growing plant tissue (Taylor et al., 2002).

In order to overcome the excessive ROIs-generation, the plants possess a highly sophisticated and efficient antioxidative defense system. The disruption of cellular homeostasis and stressinduced damages are mitigated by the action of various enzymatic (superoxide dismutase, SOD; catalase, CAT; peroxidase, POD; glutathione peroxidase, GPX; glutathione reductase, GR; glutathione-S-transferase, GST) and non-enzymatic (glutathione, GSH; ascorbic acid or vitamin C, Vc; $\alpha$-tocopherol or vitamin E, Ve; and carotenoids) antioxidants (Foyer and Noctor, 2005; Gill and Tuteja, 2010; Anjum et al., 2015; Chen et al., 2015). In plants, the levels of ROIs are regulated by the rate of their production/generation and the extent of neutralization by enzymatic and/or non-enzymatic antioxidants. It has been well documented that the activities of antioxidants correlates with the tolerance ability of the plant (Gill and Tuteja, 2010). Chillingtolerant maize (Hodges et al., 1997; Taka, 2004), cucumber (Kang and Saltveit, 2002), and rice (Huang and Guo, 2005) cultivars had higher antioxidation activities than the sensitive cultivars. Likewise, the enhanced activities of antioxidants protected the plants from oxidative stress caused by the deprivation/deficiency of N (Tewari et al., 2007; Kováčik et al., 2014), P (Tewari et al., 2004, 2007), or K (Tewari et al., 2007; Hafsi et al., 2011).

Seed priming, a controlled hydration technique, has emerged as an effective and indispensable approach to enhance the emergence, seedling vigor and stress tolerance of many field crops including rice (Jisha et al., 2013; Paparella et al., 2015). Plants raised from primed seeds show vigorous start and greater stress tolerance primarily due to more efficient energy metabolism, osmotic adjustment, enlarged embryo, enhanced enzyme activation, and quick cellular defense responses (Jisha et al., 2013). In recent years, seed priming has been proved as a promising approach in modern stress management as it protects plants against pathogens and abiotic stresses without affecting fitness (Chen and Arora, 2013; Jisha et al., 2013). Xu et al. (2011) found that the seed priming improved the chilling tolerance in tobacco during seed germination and seedling growth by the activation of antioxidant system in the plant tissues. Seed priming-induced enhancements in antioxidative defense system of rice seedlings have been well-reported in past (Khaliq et al., 2015; Zheng et al., 2015; Hussain et al., 2016).

In recent years, the generations and scavenging system of ROIs have attracted increasing attention because of their important role in the defense of plants against biotic and abiotic stresses. Although the occurrence of oxidative stress by low temperature (Xu et al., 2011; Hussain et al., 2016), N-deprivation (Kandlbinder et al., 2004; Tewari et al., 2007), P-deprivation (Juszczuk et al., 2001; Malusà et al., 2002; Kandlbinder et al., 2004), and K-deprivation (Shin and Schachtman, 2004; Cakmak, 2005) is well reported in different plant species, the comparative and interactive influence of nutrient deprivation $(\mathrm{N}, \mathrm{P}$, or $\mathrm{K})$ and chilling stress on redox and antioxidant status of rice seedlings remains unexplored. Moreover, the role of seed priming on production and detoxification of ROIs under these stress factors is poorly known. Therefore, the present study was performed, for the first time, to characterize the behavior of growth, ROIsproduction, and their detoxification in primed and non-primed rice seedlings under chilling stress and $\mathrm{N}-, \mathrm{P}-$, or K-deprivation.

\section{MATERIALS AND METHODS}

\section{Plant Material}

Rice (Oryza sativa L.) cultivar "Huanghuazhan" was used in the present experiment. Huanghuazan is an inbred Indica cultivar, which is widely cultivated by the rice farmers in central China (Liu et al., 2015). The initial germination and moisture content of the seeds were $>95$ and $<10 \%$ (on dry weight basis), respectively. To minimize contamination during priming, seeds were surface sterilized with $2.63 \% \mathrm{NaOCl}$ solution (household bleach diluted 1:1 with sterile water) for $30 \mathrm{~min}$ and rinsed three times with sterile distilled water. Culture tools 
and hydroponic solution were also sterilized (autoclaved) prior to use.

\section{Experimentation}

The seed-priming treatments were hydropriming (HP; distilled water), chemical priming (Se: $60 \mu \mathrm{M}$ selenium) and hormonal priming (SA: $100 \mathrm{mg} \mathrm{L}^{-1}$ salicylic acid). A non-primed control (NP) was maintained for comparison. The effective levels of these priming solutions were pre-optimized based on rice emergence and early seedling growth performance. Seeds were primed in the dark at $25^{\circ} \mathrm{C}$ for $24 \mathrm{~h}$ with constant gentle agitation. The ratio of seed weight to solution volume (w/v) was $1: 5$. The priming solution was changed every $12 \mathrm{~h}$ (Hussain et al., 2015). After $24 \mathrm{~h}$, the primed seeds were washed with distilled water for $2 \mathrm{~min}$, surface-dried using blotting paper, and transferred to an airdrying oven at $25^{\circ} \mathrm{C}$ for $48 \mathrm{~h}$ to reduce the moisture content to $<10 \%$.

The chilling stress (CS) was imposed from the start of experiment in growth chamber by maintaining the day and night temperatures at $18^{\circ} \mathrm{C}$, while the temperature (day/night) for control $(\mathrm{Cn})$ treatment was set at $28 \mathrm{C}$ in a separate growth chamber. Under $\mathrm{Cn}$ as well as CS conditions, a 12-h light period and humidity of $60 \%$ were maintained throughout the study.

Different nutrient management regimes were, [1] sufficient nutrient supply (All Nut), [2] N-deprivation (-N), [3] P-deprivation (-P), and [4] K-deprivation (-K). In All Nut treatments, the nutrient solution, as described by the International Rice Research Institute (Yoshida et al., 1976) was used. The solution for All Nut treatments contained $1 \mathrm{mM}$ $\left(\mathrm{NH}_{4}\right)_{2} \mathrm{SO}_{4}, 1 \mathrm{mM} \mathrm{NaH} \mathrm{PO}_{4}, 1 \mathrm{mM} \mathrm{KCl}, 1 \mathrm{mM} \mathrm{Ca}\left(\mathrm{NO}_{3}\right)_{2}$, $2 \mathrm{mM} \mathrm{Na}_{2} \mathrm{SiO}_{3} .9 \mathrm{H}_{2} \mathrm{O}, 1 \mathrm{mM} \mathrm{MgSO}{ }_{4} .7 \mathrm{H}_{2} \mathrm{O}, 10 \mu \mathrm{M} \mathrm{H} \mathrm{BO}_{3}$, $1 \mu \mathrm{M} \mathrm{ZnSO}_{4} .7 \mathrm{H}_{2} \mathrm{O}, 0.5 \mu \mathrm{M} \mathrm{MnSO}_{4} \cdot \mathrm{H}_{2} \mathrm{O}, 0.1 \mu \mathrm{M} \mathrm{CuSO}_{4} .5 \mathrm{H}_{2} \mathrm{O}$, $0.05 \mu \mathrm{M}\left(\mathrm{NH}_{4}\right) 6 \mathrm{Mo}_{7} \mathrm{O}_{24} \cdot 4 \mathrm{H}_{2} \mathrm{O}$, and $20 \mu \mathrm{M}$ FeNa-EDTA. In treatments of $\mathrm{N}-, \mathrm{P}-$, and $\mathrm{K}$-deprivation, all other nutrients were applied at full concentrations except $\left(\mathrm{NH}_{4}\right)_{2} \mathrm{SO}_{4}, \mathrm{NaH}_{2} \mathrm{PO}_{4}$, and $\mathrm{KCl}$, respectively. Different nutrient solutions were imposed at 4 days after sowing (DAS), and all the solutions were renewed after every two days during the course of the study. The $\mathrm{pH}$ of solutions was maintained at $6.6 \pm 0.2$ before supplying to the plants.

Plastic pots ( $30 \mathrm{~cm} \times 20 \mathrm{~cm} \times 15 \mathrm{~cm}$ ), containing four liters of respective solution and a floating board on the surface of solution, with four separated sections (for seed priming treatments), were used (Figure 1). Twenty seeds of each seed priming treatment were sown in the separated section of board. The experiment was laid out in a completely randomized design with six independent replicates.

\section{Evaluation of Rice Seedling Growth and Oxidative Metabolism}

Seedlings were harvested at 18 DAS, and the photographs (Figure 1) were taken 3 days prior to harvesting (15 DAS). Shoot and root length of ten randomly selected seedlings from each replication were measured. Seedlings of each replicate were dissected into roots and shoots, and their fresh weight was recorded immediately using digital electric balance.
All the biochemical analyses were carried out by using fresh leaves samples. Malondialdehyde (MDA) was extracted with 5\% trichloroacetic acid (TCA) and was measured using a thiobarbituric acid reaction (Bailly et al., 1996) in order to determine the level of lipid peroxidation. Hydrogen peroxide $\left(\mathrm{H}_{2} \mathrm{O}_{2}\right)$ content was measured spectrophotometrically at $390 \mathrm{~nm}$ (Patterson et al., 1984). The reaction mixture consisted $0.5 \mathrm{ml}$ $0.1 \%$ TCA leaf extract supernatant, $0.5 \mathrm{ml}$ of the potassium phosphate buffer ( $\mathrm{pH} 7.0$ ), and $1 \mathrm{ml}$ of $1 \mathrm{M}$ potassium iodide. The amount of $\mathrm{H}_{2} \mathrm{O}_{2}$ in the leaves of rice seedlings was calculated using a standard curve prepared with known concentrations of $\mathrm{H}_{2} \mathrm{O}_{2}$. The MDA as well as $\mathrm{H}_{2} \mathrm{O}_{2}$ content was expressed as $\mu \mathrm{M} \mathrm{g}^{-1} \mathrm{FW}$. The contents of hydroxyl ion $\left(\mathrm{OH}^{-}\right)$and superoxide anion radical $\left(\mathrm{O}_{2}^{\bullet-}\right)$ in the leaves of rice seedlings were determined using the commercial $\mathrm{OH}^{-}$assay kit (A018) and $\mathrm{O}_{2}^{\bullet-}$ assay kit (A052), respectively, obtained from Nanjing Jiancheng Bioengineering Institute, China ${ }^{1}$. The $\mathrm{OH}^{-}$was expressed as units $\mathrm{mg}^{-1}$ protein, and one unit was the amount required to reduce $1 \mathrm{M}$ of $\mathrm{H}_{2} \mathrm{O}_{2}$ in the reaction mixture per minute at $37^{\circ} \mathrm{C}$. The $\mathrm{O}_{2}^{\bullet-}$ was demonstrated as units $\mathrm{g}^{-1}$ protein, and one unit was equivalent of the value required to inhibit superoxide anion by $1 \mathrm{mg}$ of $\mathrm{Vc}$ for $40 \mathrm{~min}$ at $37^{\circ} \mathrm{C}$.

The activities of ROIs-producing enzymes viz., MAO and XOD were measured by using the kit-A002 and kitA034, respectively. The activities of both these enzymes were demonstrated as follows: 1 unit $\mathrm{mg}^{-1}$ protein for MAO was defined as the amount of enzyme that increased the absorbance by 0.01 at $37^{\circ} \mathrm{C}$ in 1 hour; 1 unit $\mathrm{g}^{-1}$ protein for XOD was defined as $1 \mathrm{~g}$ of protein required to transform $1 \mu \mathrm{M}$ of hypoxanthine to xanthine in $1 \mathrm{~min}$ at $37^{\circ} \mathrm{C}$.

The activities of enzymatic antioxidants were detected by using the commercial kits in accordance with the manufacturer's instructions. The kits for SOD (A001), POD (A084-3), CAT (A007-2), GPX (A005), GR (A062), and GST (A004) were purchased from the same company as mentioned above. The absorbance readings of SOD, POD, CAT, GPX, GR, and GST were detected at $\mathrm{OD}_{550}, \mathrm{OD}_{420}, \mathrm{OD}_{405}, \mathrm{OD}_{412}, \mathrm{OD}_{340}$, and $\mathrm{OD}_{412}$, respectively (Tecan-infinite M200, Switzerland). The SOD, POD, CAT, GPX, and GST activities were expressed as units $\mathrm{mg}^{-1}$ protein, while GR activity was demonstrated as units $\mathrm{g}^{-1}$ protein. The units of the antioxidant enzyme activities were defined as follows: one unit of SOD activity was the amount of enzyme required to decrease the reference rate to $50 \%$ of maximum inhibition; one unit of POD activity was defined as the amount of enzyme necessary for the decomposition of $1 \mu \mathrm{g}$ substrate in $1 \mathrm{~min}$ at $37^{\circ} \mathrm{C}$; one unit of CAT activity was defined as the amount of enzyme required to decompose the $1 \mu \mathrm{M} \mathrm{H}_{2} \mathrm{O}_{2}$ in 1 second at $37^{\circ} \mathrm{C}$; One unit is GPX activity was the amount of enzyme required to oxidize $1 \mu \mathrm{M} \mathrm{GSH}$ in 1 minute at $37^{\circ} \mathrm{C}$; one unit of GR activity was defined as the amount of enzyme depleting $1 \mathrm{mM}$ NADPH in $1 \mathrm{~min}$; one unit of GST activity was defined as the amount of enzyme depleting $1 \mu \mathrm{M}$ GSH in $1 \mathrm{~min}$.

The GSH, Vc, and Ve (kit-A008) content in leaves of rice seedlings were measured using the kit-A006, kit-A009, and kitA008, respectively. The absorbance for GSH, Vc, and Ve were

\footnotetext{
${ }^{1}$ www.njjcbio.com
} 


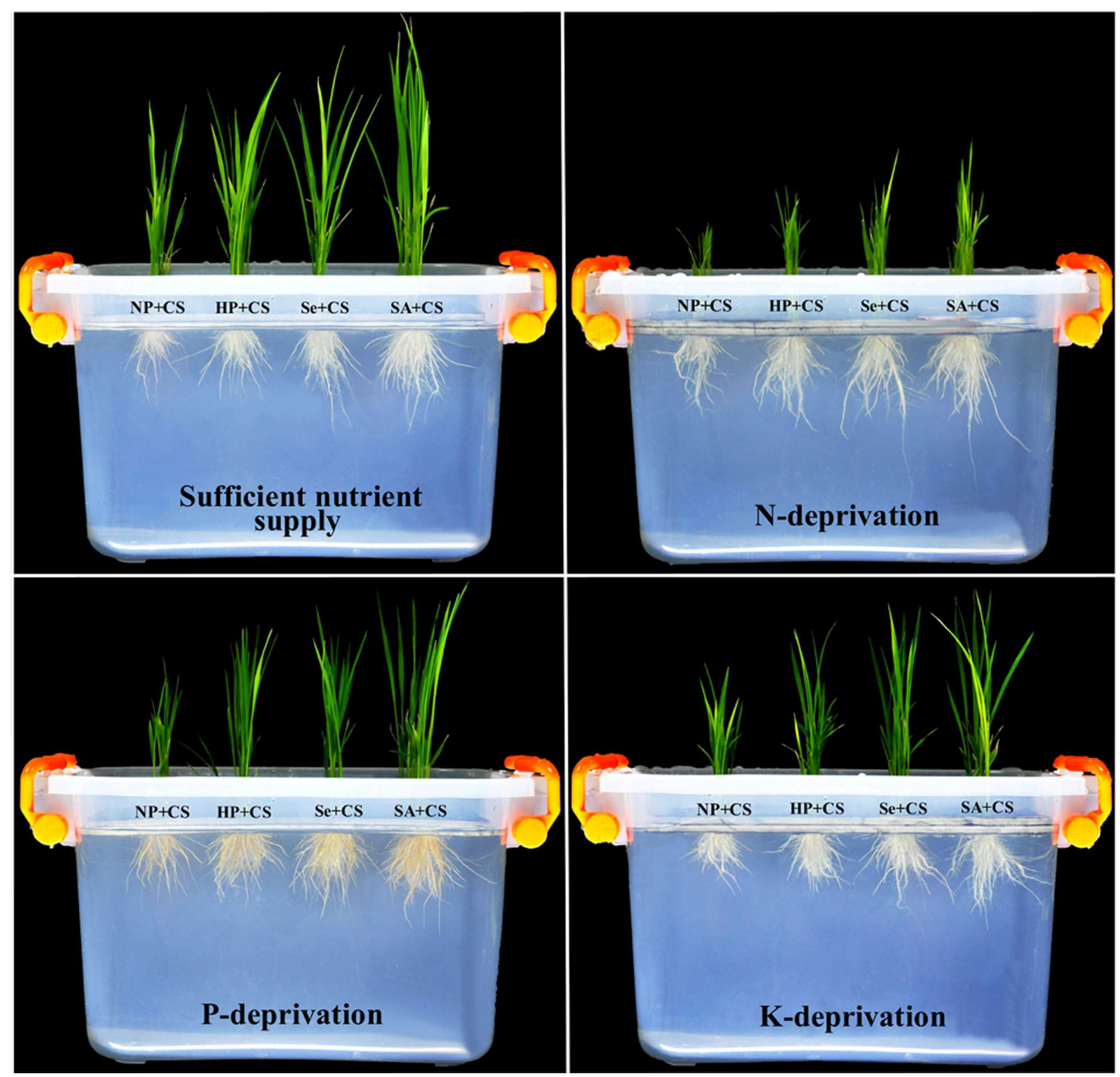

FIGURE 1 | Pictorial view of primed and non-primed rice seedlings grown under chilling stress and different nutrient management regimes. Photographs were taken at $15 \mathrm{DAS}$ for treatments under chilling stress $\left(18^{\circ} \mathrm{C}\right)$. NP+CS: no priming and $18^{\circ} \mathrm{C}$ temperature, $\mathrm{HP}+\mathrm{CS}$ : hydropriming and $18^{\circ} \mathrm{C}$ temperature, Se+CS: selenium priming and $18^{\circ} \mathrm{C}$ temperature, SA+CS: salicylic acid priming and $18^{\circ} \mathrm{C}$ temperature.

recorded at $\mathrm{OD}_{420}, \mathrm{OD}_{536}$, and $\mathrm{OD}_{533}$ (Tecan-infinite M200, Swit), respectively. The GSH content were expressed as $\mu \mathrm{Mg} \mathrm{g}^{-1}$ protein, the $\mathrm{Vc}$ as $\mu \mathrm{g} \mathrm{mg}^{-1}$ protein, and $\mathrm{Ve}$ as $\mu \mathrm{gg}^{-1}$ tissue fresh weight.

The commercial kit-A015 was used for determination of total antioxidant capability (T-AOC). The absorbance for T-AOC was measured at $\mathrm{OD}_{520}$ and data were expressed as unit $\mathrm{mg}^{-1}$ protein. One unit of T-AOC was defined as the amount that increased the absorbance by 0.01 at $37^{\circ} \mathrm{C}$.

\section{Statistical Analysis}

Data were statistically analyzed following analysis of variance using Statistix 8.1 software (Analytical Software, Tallahassee, FL, USA). Mean variance of the data was analyzed using the Tukey's HSD $(P \leq 0.05)$ test (Gomez and Gomez, 1984).
Comparisons were made and discussed as: (1) among different nutrient management regimes (All Nut, N-deprivation, P-deprivation, and K-deprivation), (2) between non-primed rice seedlings of control temperature $(\mathrm{NP}+\mathrm{Cn})$ vs. chilling stress $(\mathrm{NP}+\mathrm{CS})$ under different nutrient management regimes, and (3) between $\mathrm{NP}+\mathrm{CS}$ vs. primed rice seedlings $(\mathrm{HP}+\mathrm{CS}, \mathrm{Se}+\mathrm{CS}, \mathrm{SA}+\mathrm{CS})$ under different nutrient management regimes.

\section{RESULTS}

\section{Seedling Growth}

Pronounced variations in the seedling growth of rice were observed under the influence of chilling stress, nutrient 

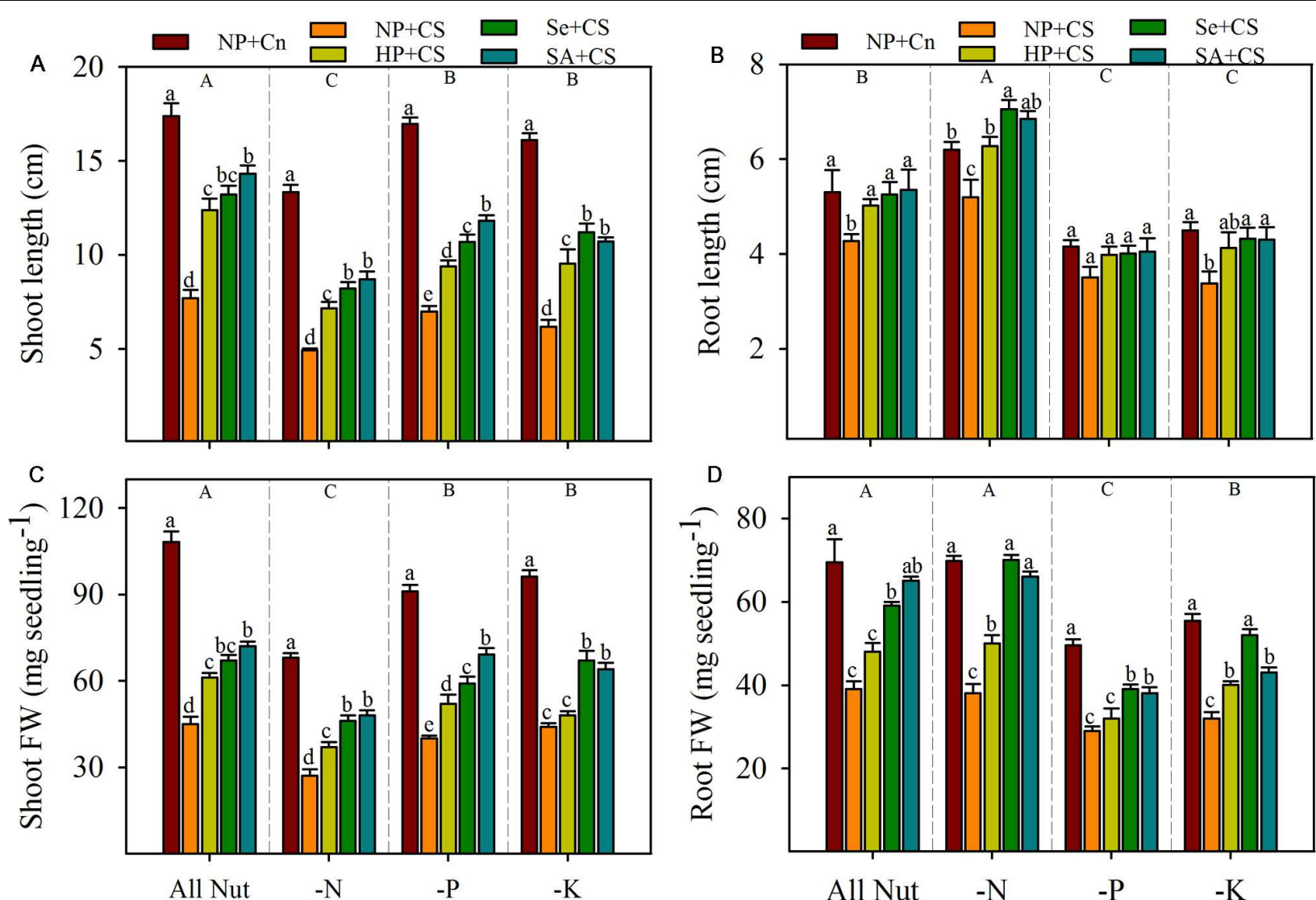

Nutrient management regimes

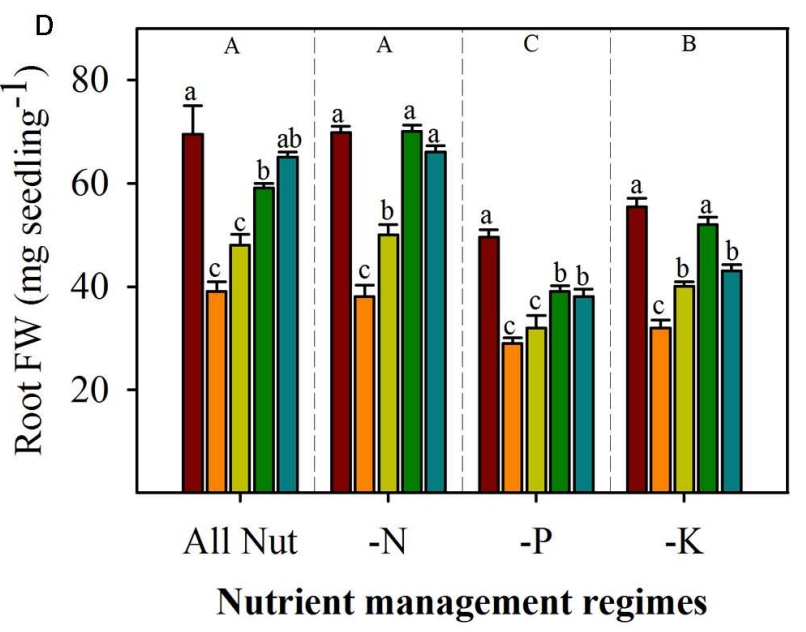

FIGURE 2 | Shoot length (A), root length (B), shoot fresh weight (C), and root fresh weight (D) of primed and non-primed rice seedlings as influenced by chilling stress and different nutrient management regimes. Vertical bars above mean indicate standard error of six replicates. Small alphabetical letters (a, b, c. . ) above means show the differences $(P \leq 0.05)$ among treatments with in a nutrient management regime, while capital alphabetical letters $(A, B, C .$. reveal the differences $(P \leq 0.05)$ among different nutrient management regimes. NP+Cn: no priming and $28^{\circ} \mathrm{C}$ temperature, $\mathrm{NP}+\mathrm{CS}$ : no priming and $18^{\circ} \mathrm{C}$ temperature, $\mathrm{HP}+\mathrm{CS}$ : hydropriming and $18^{\circ} \mathrm{C}$ temperature, Se+CS: selenium priming and $18^{\circ} \mathrm{C}$ temperature, $\mathrm{SA}+\mathrm{CS}$ : salicylic acid priming and $18^{\circ} \mathrm{C}$ temperature, All Nut: sufficient nutrient supply, -N: nitrogen-deprivation, -P: phosphorus-deprivation, -K: potassium-deprivation.

deprivation, and seed priming treatments (Figures $\mathbf{1}$ and 2). Irrespective of chilling stress and seed priming treatments, shoot length and shoot fresh weight of rice were significantly reduced after deprivation of $\mathrm{N}, \mathrm{P}$, or $\mathrm{K}$, however, such reductions of shoot growth were more for $\mathrm{N}$-deprived seedlings (Figures 2A,C). Compared with All Nut, root length was significantly increased, while root fresh weight was statistically similar in $\mathrm{N}$-deprived seedlings, indicating that roots were lengthy but less fibrous under $\mathrm{N}$-deprived conditions. Nevertheless, root length as well as root fresh weight of rice were significantly reduced in $\mathrm{P}$ - or K-deprived seedlings (Figures 2B,D).

Chilling stress was found to severely reduce the seedling growth of rice under sufficient nutrients supply as well as nutrient deprived conditions. Compared with $\mathrm{NP}+\mathrm{Cn}$, root and shoot growth attributes of rice were significantly reduced in NP+CS in all the nutrient management regimes except root length in P-deprivation treatment (Figures 2A-D). Chilling-induced reductions in shoot growth of rice were more compared with those in root growth. Likewise, root length was generally less sensitive to chilling stress than root fresh weight. Effects of seed priming were also apparent in alleviating the stress-induced inhibitions of rice seedling growth (Figures 2A-D). Compared with $\mathrm{NP}+\mathrm{CS}$, all the seed priming treatments significantly increased the shoot length and shoot fresh weight of rice in all the nutrient management regimes except $\mathrm{HP}+\mathrm{CS}$ for shoot fresh weight under K-deprivation. The Se+CS and SA+CS were generally more effective than $\mathrm{HP}+\mathrm{CS}$ for enhancing shoot growth of rice (Figures 2A,C). These two priming treatments $(\mathrm{Se}+\mathrm{CS}$ and $\mathrm{SA}+\mathrm{CS}$ ) were also found to significantly increase the root growth attributed of rice compared with $\mathrm{NP}+\mathrm{CS}$ expect for root length under P-deprived conditions (Figures 2B,D).

\section{Lipid Peroxidation and ROIs-Accumulation}

Data regarding the rate of lipid peroxidation and accumulation of ROIs in the leaves of primed and non-primed rice seedlings 

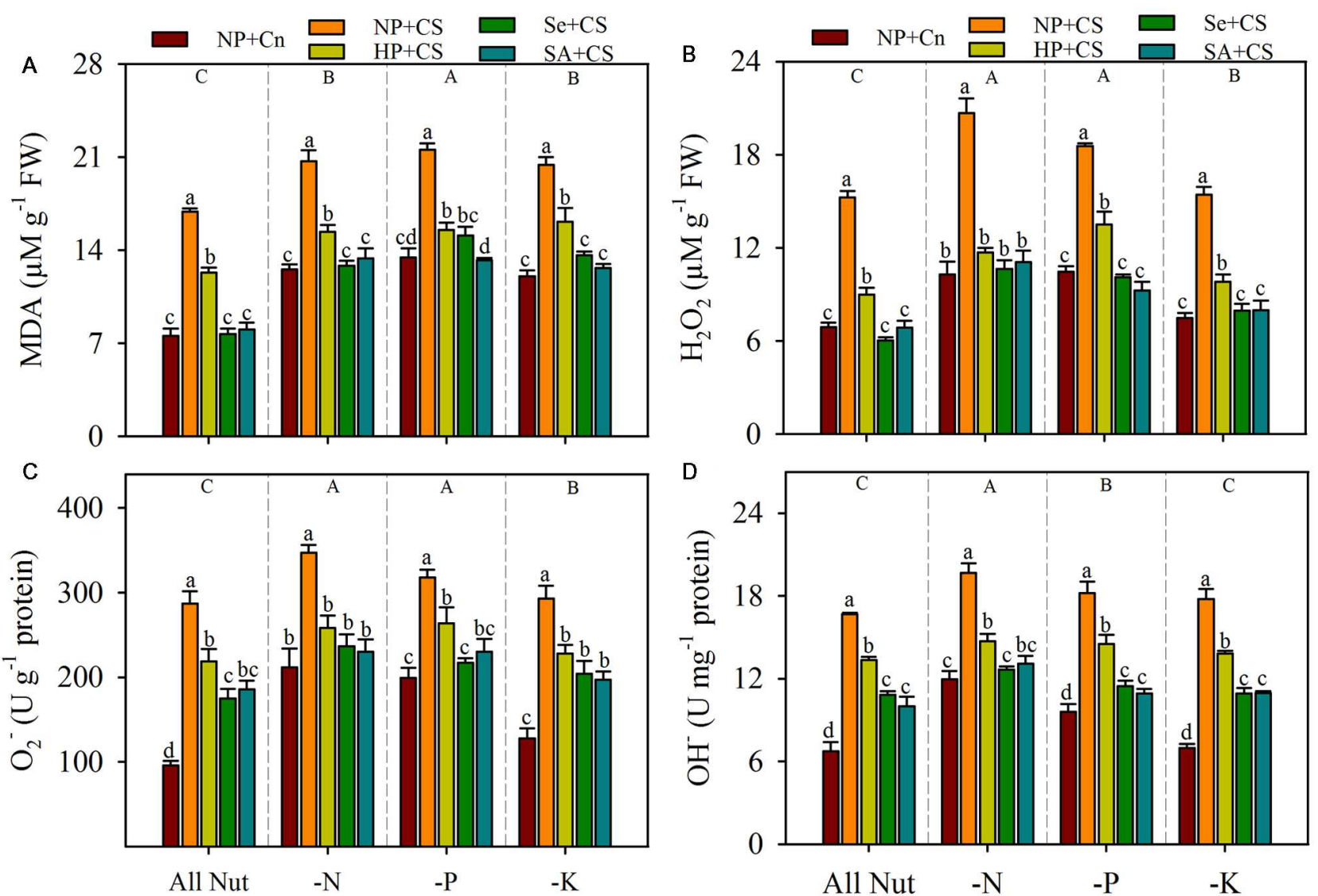

Nutrient management regimes

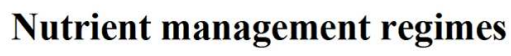

FIGURE 3 | Lipid peroxidation and accumulation of reactive oxygen intermediates (ROIs) in primed and non-primed rice seedlings under chilling stress and different nutrient management regimes. MDA content (A), $\mathrm{H}_{2} \mathrm{O}_{2}$ (B), $\mathrm{O}_{2}^{--}$(C), and $\mathrm{OH}^{-}$(D). Vertical bars above mean indicate standard error of six replicates. Small alphabetical letters $(a, b, c \ldots)$ above means show the differences $(P \leq 0.05)$ among treatments with in a nutrient management regime, while capital alphabetical letters (A, B, C . . ) reveal the differences $(P \leq 0.05)$ among different nutrient management regimes. Description of treatments is given in Figure 2.

under chilling stress and different nutrient management regimes are shown in Figure 3. The lipid peroxidation rates, as indicated by MDA content, were significantly enhanced with deprivation of any mineral nutrient, the maximum for P-deprived seedlings (Figure 3A). Likewise, the concentrations of $\mathrm{H}_{2} \mathrm{O}_{2}$ and $\mathrm{O}_{2}^{\bullet-}$ were increased to a significant level after nutrient deprivation, particularly for $\mathrm{N}$ or $\mathrm{P}$ (Figures 3B,C). The concentrations of $\mathrm{OH}^{-}$ were significantly higher in $\mathrm{N}$ - or P-deprived seedlings, but not in K-deprived relative to that in All Nut treatment (Figure 3D). Chilling stress triggered the lipid peroxidation and production of ROIs, thus, the accumulations of MDA, $\mathrm{H}_{2} \mathrm{O}_{2}, \mathrm{O}_{2}^{\bullet-}$, and $\mathrm{OH}^{-}$were significantly higher in $\mathrm{NP}+\mathrm{CS}$ treatment under all the nutrient management regimes compared with $\mathrm{NP}+\mathrm{Cn}$. Seed priming treatments were effective in mitigating the stress-induced enhancement in MDA and ROIs-accumulation. Therefore, the rice seedlings emerged from primed seeds manifested significantly lower MDA contents as well as ROIs-accumulation (Figures 3A-D). The $\mathrm{Se}+\mathrm{CS}$ and $\mathrm{SA}+\mathrm{CS}$ treatments were generally more effective, and were statistically similar with each other for most of the cases (Figures 3A-D).

\section{Monoamine Oxidase and Xanthine Oxidase Activities}

The activities of ROIs-producing enzymes (MAO and XOD) were significantly enhanced with deprivation of $\mathrm{N}$ or $\mathrm{P}$, but remained unaffected with K-deprivation (Figure 4). The maximum activities of both these enzymes were recorded in $\mathrm{N}$-deprived seedlings. Chilling stress triggered the activities of MAO and XOD, therefore, significantly higher levels of both these enzymes were observed in NP+CS treatments compared with $\mathrm{NP}+\mathrm{Cn}$, in all the nutrient management regimes (Figure 4). All the seed priming treatments effectively assuaged the stressinduced enhancements in activities of these enzymes, and recorded significantly lower levels of $\mathrm{MAO}$ and $\mathrm{XOD}$, compared with $\mathrm{NP}+\mathrm{CS}$. Interesting, the activities of both these enzymes in $\mathrm{Se}+\mathrm{CS}$ and SA+CS treatments were statistically similar or lower than those in NP+Cn, under all the nutrient management 

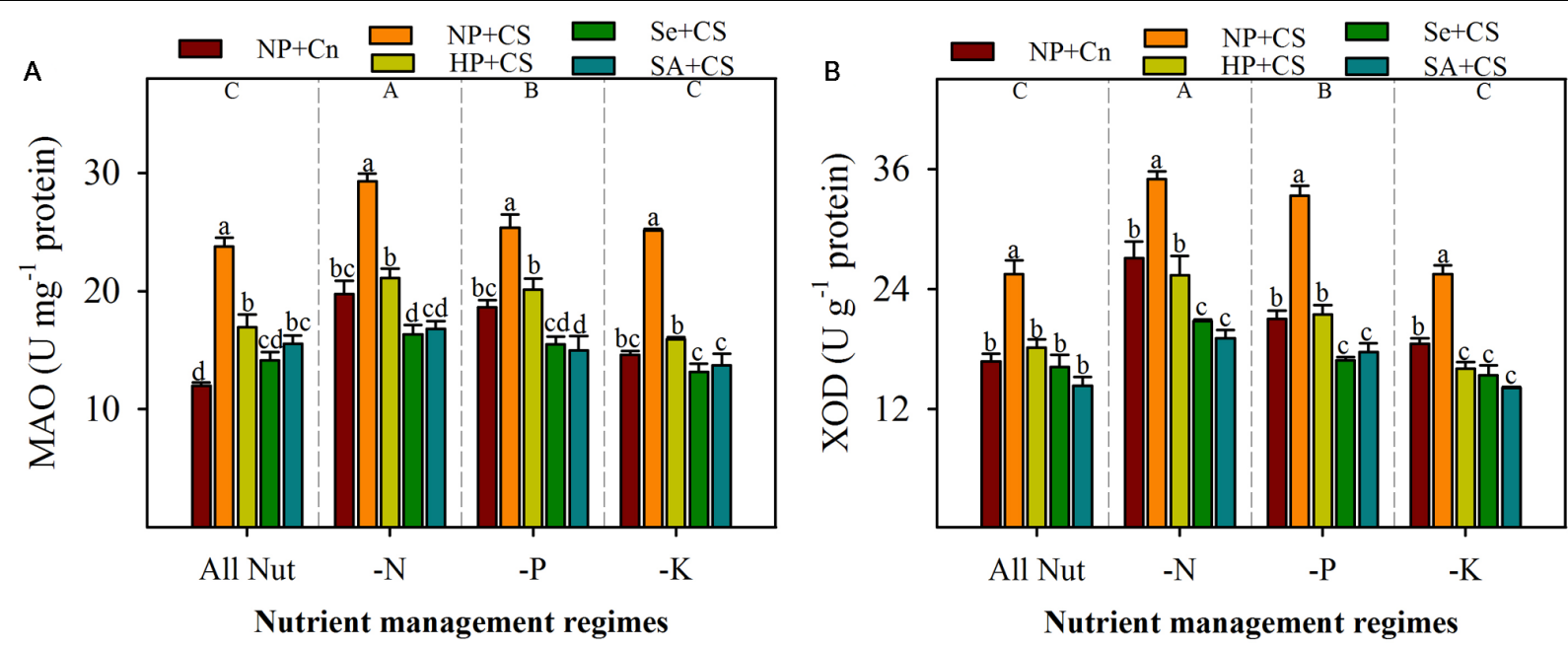

FIGURE 4 | Activities of monoamine oxidase (MAO) (A) and XOD (B) in primed and non-primed rice seedlings under chilling stress and different nutrient management regimes. Vertical bars above mean indicate standard error of six replicates. Small alphabetical letters (a, b, c. .) above means show the differences $(P \leq 0.05)$ among treatments with in a nutrient management regime, while capital alphabetical letters $(A, B, C \ldots)$ reveal the differences $(P \leq 0.05)$ among different nutrient management regimes. Description of treatments is given in Figure 2.

regimes except MAO activity in SA+CS for All Nut treatment (Figure 4).

\section{Enzymatic Antioxidants}

Data regarding antioxidant enzymes activities in the leaves of rice seedlings under the influence of different nutrient management regimes, chilling stress and seed priming treatments are shown in Figure 5. The SOD activity in rice seedlings did not alter significantly under deprivation of any nutrient (Figure 5A). The CAT and POD activities were significantly increased with N- or P-deprivation, while GPX and GR activities were reduced, particularly with $\mathrm{P}$-deprivation (Figures 5B-E). The K-deprived seedlings recorded significantly higher activities of CAT and GR, nevertheless, POD and GPX activities under K-deprivation were statistically similar with All Nut. The GST activity was unaffected by $\mathrm{N}$ - or P-deprivation, but reduced with K-deprivation (Figure 5F). The effects of chilling stress on antioxidant activities were apparent, but variable with nutrient management regimes. The SOD activity was induced under chilling stress in $\mathrm{P}$ - and $\mathrm{K}$-deprived seedlings, but the effects were non-significant. The CAT activities in NP+Cn and NP+CS treatments were statistically similar under All Nut, P-deprivation and K-deprivation, while, NP+CS recorded significantly higher CAT activity under N-deprivation compared with $\mathrm{NP}+\mathrm{Cn}$. Interestingly, the POD and GR activities were significantly enhanced after chilling stress in all the nutrient management regimes. Chilling stress decreased the activities of GPX under All Nut treatments, and GST under All Nut and K-deprivation treatments. The GPX as well as GST were unaffected by chilling stress, under $\mathrm{N}$ - or P-deprivation (Figure 5). The seed priming treatments generally triggered the activities of all antioxidants, but the effects were variable depending on stress conditions. For example, $\mathrm{Se}+\mathrm{CS}$ and SA+CS significantly increased the activities of CAT, POD, and GPX in All Nut treatments, CAT under
$\mathrm{N}$ - or P-deprivation, and POD under K-deprivation treatments, compared with NP+CS (Figure 5). More apparently, GR activity was significantly enhanced in Se+CS and SA+CS treatments compared with $\mathrm{NP}+\mathrm{CS}$ under all the nutrient management regimes (Figure 5E).

\section{Non-enzymatic Antioxidants}

The GSH and Vc content in the leaves of rice seedlings were significantly reduced with $\mathrm{N}$-deprivation, but these both antioxidants were unaffected by $\mathrm{P}$ - or K-deprivation (Figures 6A,B). The Ve content were significantly reduced with the deprivation of any mineral nutrient (Figure 6C). Chilling stress did not affect the GSH and Ve content under all the nutrient management regimes, except GSH content were significantly enhanced by chilling stress in N-deprived seedlings. Chilling stress significantly decreased the Vc content in All Nut and K-deprived conditions, but had no affect under N-or $\mathrm{P}$-deprivation. The Ve content were unaffected by seed priming treatments, however, GSH contents were significantly enhanced by SA+CS under $\mathrm{N}$ - or K-deprivation. The SA+CS also recorded significantly higher Vc content under All Nut, P-deprived or K-deprived conditions, compared with NP+CS (Figure 6).

\section{Total Antioxidant Capability}

The T-AOC in the leaves of rice seedlings was triggered with nutrient deprivation (Figure 6D). Compared with All Nut, the Nand K-deprived seedlings recorded significantly higher T-AOC. Chilling stress was found to significantly enhance the T-AOC of rice seedlings under all the nutrient management regimes except $\mathrm{N}$-deprivation, where $\mathrm{NP}+\mathrm{Cn}$ and $\mathrm{NP}+\mathrm{CS}$ recorded statistically similar T-AOC (Figure 6D). Seed priming regulated the T-AOC in rice seedlings under stress conditions. Compared with $\mathrm{NP}+\mathrm{CS}$, the $\mathrm{Se}+\mathrm{CS}$ and $\mathrm{SA}+\mathrm{CS}$ recorded significantly higher T-AOC under all the nutrient management regimes (Figure 6D). 

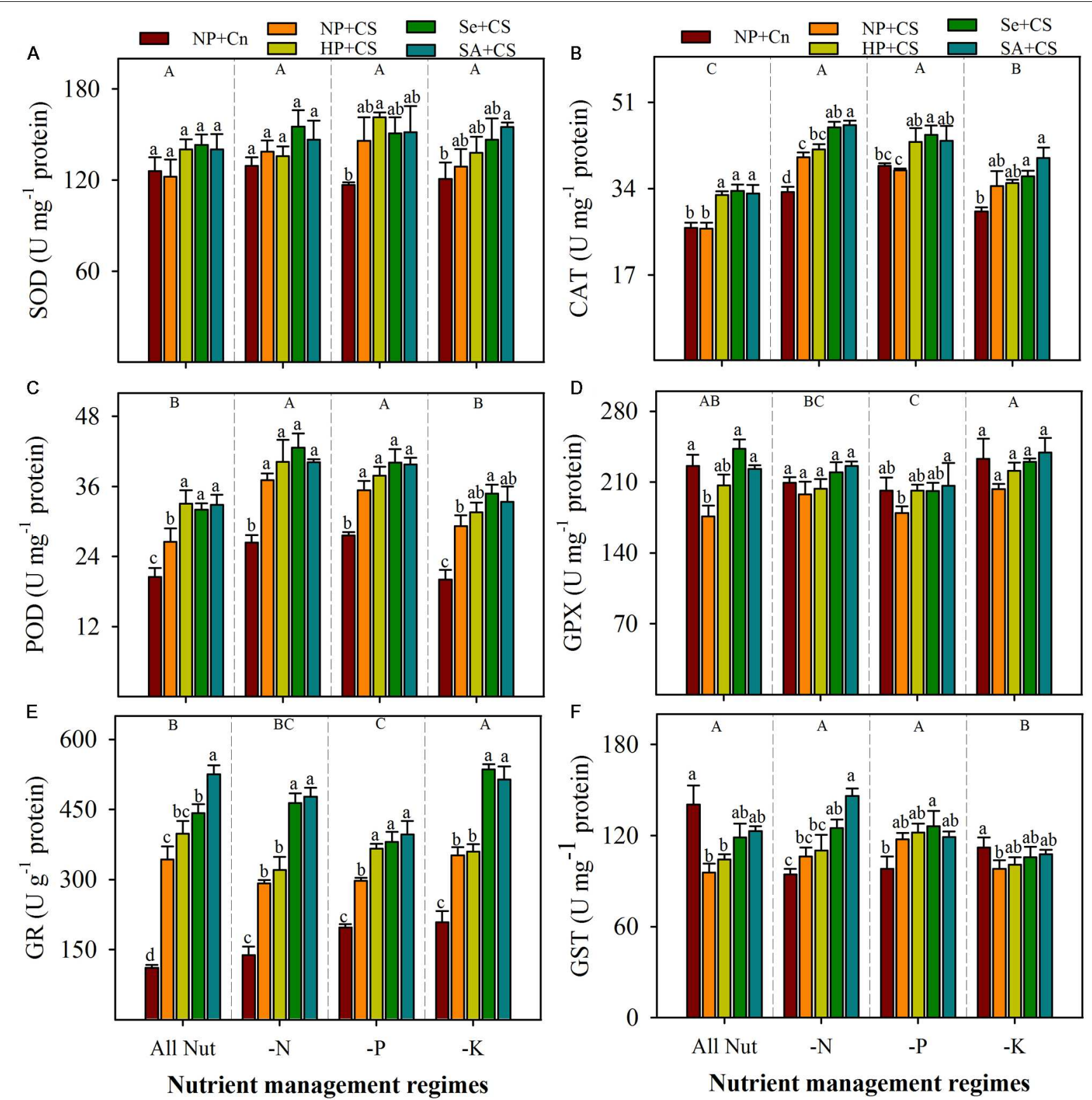

Nutrient management regimes

FIGURE 5 | Activities of enzymatic antioxidants in primed and non-primed rice seedlings under chilling stress and different nutrient management regimes. SOD (A), CAT (B), POD (C), GPX (D), GR (E), and GST (F). Vertical bars above mean indicate standard error of six replicates. Small alphabetical letters $(a, b, c \ldots)$ above means show the differences $(P \leq 0.05)$ among treatments with in a nutrient management regime, while capital alphabetical letters $(A, B, C \ldots)$ reveal the differences $(P \leq 0.05)$ among different nutrient management regimes. Description of treatments is given in Figure 2.

\section{DISCUSSION}

Under natural conditions, plants usually face with different kinds of abiotic stresses on a daily, seasonal or annual basis. Rice, being a tropical species is extremely sensitive to low temperature particularly at early growth stages. Yoshida (1981) reported that the germination and early growth of rice can be hampered under daily mean temperature of $<20^{\circ} \mathrm{C}$. In our recent laboratory and field studies, we have found that low temperature $\left(18^{\circ} \mathrm{C}\right.$ or below) severely hampered the growth of rice seedlings, and disrupted the associated physiological and metabolic processes (Hussain et al., 2016; Wang et al., 2016). In addition to temperature, optimum supply of mineral nutrients (particularly NPK) is also crucial for normal functioning of the plants, and deficiency of 

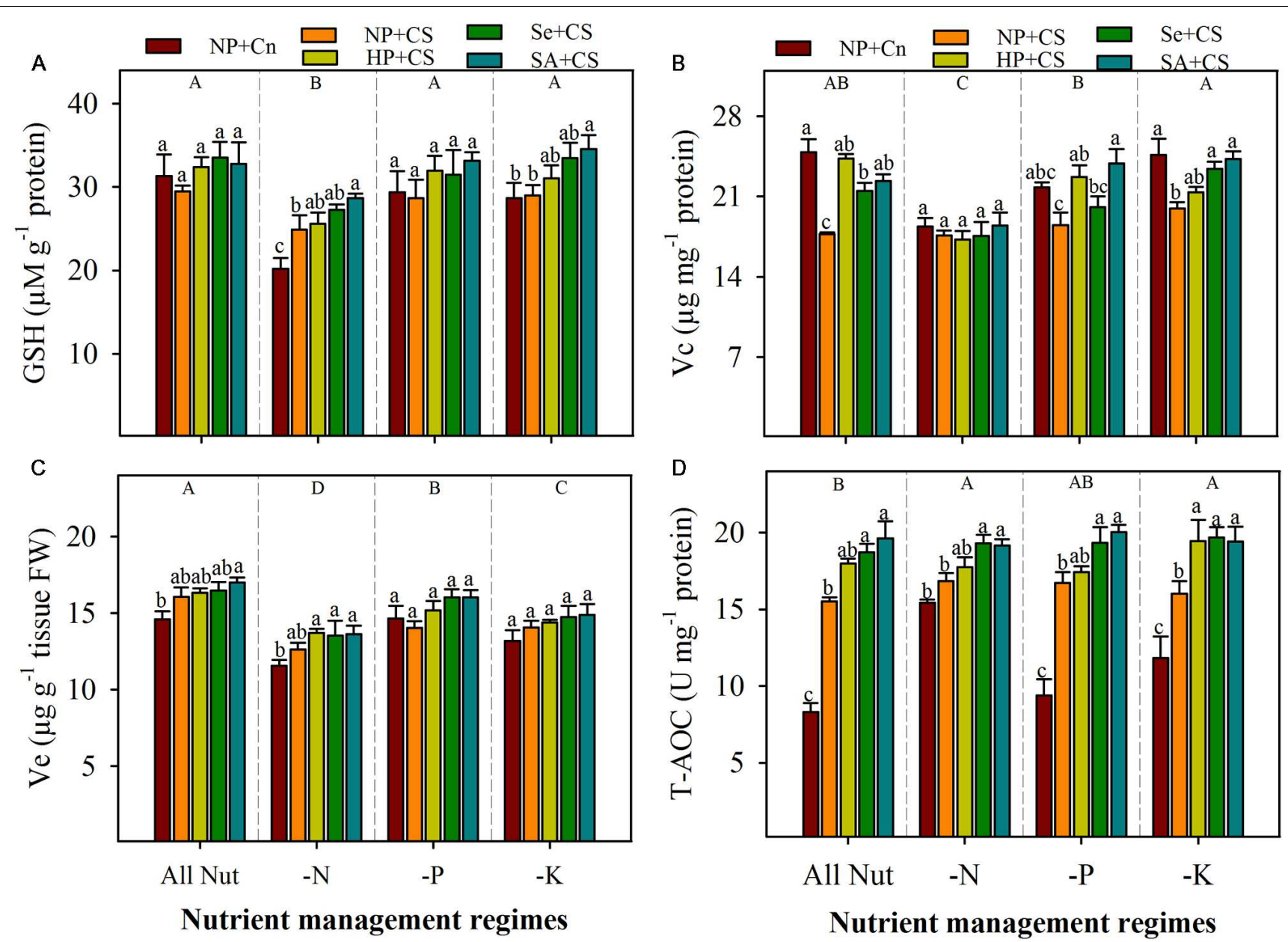

FIGURE 6 | Non-enzymatic antioxidants and total antioxidant capability of primed and non-primed rice seedlings as influenced by chilling stress and different nutrient management regimes. GSH (A), Vc (B), Ve (C), and T-AOC (D). Vertical bars above mean indicate standard error of six replicates. Small alphabetical letters $(a, b, c .$.$) above means show the differences (P \leq 0.05)$ among treatments with in a nutrient management regime, while capital alphabetical letters $(A, B, C \ldots)$ reveal the differences $(P \leq 0.05)$ among different nutrient management regimes. Description of treatments is given in Figure 2.

any nutrient challenges the survival of plants. Furthermore, to cope with a particular stress conditions (e.g., low temperature), plant require energy and sufficient resources. However, nutrient limitations/deprivation further hinders the acclimation process of plants to stress conditions. As discussed in the introduction, seed priming has been examined and used to enhance of vigor and early growth of many crop plants particularly under stress conditions (Jisha et al., 2013; Khaliq et al., 2015; Zheng et al., 2015; Hussain et al., 2016). The present study investigated, for the first time, the influence of seed priming on growth, ROIs-production, and antioxidant defense system of rice seedlings grown under sub-optimal temperature $\left(18^{\circ} \mathrm{C}\right)$ and nutrient supply $(\mathrm{N}, \mathrm{P}$, or K-deprivation).

Our results indicated a severe decline in shoot growth attributes of rice with deprivation of any mineral nutrient particularly with $\mathrm{N}$, while root fresh and dry weights were only reduced with the deprivation of $\mathrm{P}$ or $\mathrm{K}$ (Figures 1 and 2). Although the root length was higher in $\mathrm{N}$-deprived seedlings compared with All Nut, the root dry weight was same in these two nutrient management regimes (Figures $2 \mathbf{B}, \mathbf{D}$ ) suggesting that the roots of $\mathrm{N}$-deprived seedlings were less fibrous and thin. Similar responses were also observed in Arabidopsis thaliana, even after 2-days of $\mathrm{N}$ starvation (Scheible et al., 2004). In the present study, the shoots of $\mathrm{N}$-deprived seedlings were also less greenish showing the $\mathrm{N}$ deficiency. There were no apparent deficiency symptoms in the shoots of $\mathrm{P}$ - or K-deprived seedlings, although a change in root appearance was evident (Figure 1). In P-deprived seedlings, more lateral roots and shorter primary roots were observed and the color of roots was brownish, which might be due to high iron accumulation (Figure 1). Although the iron concentration was not measured in the present study, the high accumulation of iron under P deficiency is well-reported in the past (Zheng et al., 2009).

Chilling stress severely hampered the shoot and root growth of rice seedlings, which might be attributed to reduced cell division and elongation, low respiration rate, and high oxidative stress under low temperature, as observed previously (Hussain et al., 2016; Wang et al., 2016). Seed priming treatments were effective 
in alleviating the stress-induced adversities on seedling growth of rice; the Se- and SA-priming treatments were more effective than hydropriming (Figures 1 and 2). The beneficial effects of these priming reagents has been reported in the past under different stress conditions (Gunes et al., 2007; Jisha et al., 2013; Hussain et al., 2016; Wang et al., 2016).

At a whole plant level, abiotic stresses lead to the formation of excessive ROIs that can generate oxidative stress by oxidizing lipid, nucleic acids, and proteins (Mittler, 2002; Gill and Tuteja, 2010). Accordingly in the present study, chilling and nutrient deprivation triggered the production of $\mathrm{H}_{2} \mathrm{O}_{2}, \mathrm{O}_{2}^{\bullet-}$, and $\mathrm{OH}^{-}$in the rice seedlings (Figures 3B-D). The enhanced levels of these ROIs were also coincided with the higher lipid peroxidation rate (Figure 3A), which is regarded as a biochemical marker for the free radical mediated injury in plants. These results are in line with previous researchers, who observed enhanced ROIs-production and MDA content under chilling stress (Ruelland et al., 2009; Xu et al., 2011; Hussain et al., 2016), N-deprivation (Kandlbinder et al., 2004; Tewari et al., 2004, 2007), P-deprivation (Juszczuk et al., 2001; Malusà et al., 2002; Kandlbinder et al., 2004), and K- deprivation (Cakmak, 1994; Shin and Schachtman, 2004; Tewari et al., 2004, 2007). Compared with $\mathrm{N}$ - or P-deprivation, lower accumulation of ROIs was observed in K-deprived seedlings (Figure 3), which corroborate with earlier observations on K-deficient maize (Tewari et al., 2004) and mulberry (Tewari et al., 2007). All the seed priming treatments recorded significantly lower accumulation of ROIs and lipid peroxidation compared with $\mathrm{NP}+\mathrm{CS}$ (Figure 3) which indicates that oxidative stress (caused by low temperature and nutrient deprivation) and seedling damage were effectively assuaged after seed priming. Previously in rice, similar beneficial effects of seed priming have also been observed under drought (Zheng et al., 2015) and chilling stress (Hussain et al., 2016).

Generally, photorespiration, photosynthetic apparatus, and mitochondrial respiration are considered as the main sources for the generation of ROIs under normal conditions. However, some other sources such as MAO and XOD, also contribute in the active production of ROIs particularly under environmental stresses (Mittler, 2002). The MAO, a flavoprotein localized on the outer membrane of mitochondria, catalyzes the oxidative deamination of aromatic amines and produces a large quantity of $\mathrm{H}_{2} \mathrm{O}_{2}$, which ultimately contributes to an increase in the steady state concentrations of ROIs within the plant cell (Cadenas and Davies, 2000). Likewise, XOD can generate the toxic $\mathrm{O}_{2}^{\bullet-}$ as well as $\mathrm{H}_{2} \mathrm{O}_{2}$ in the plant cell (Schrader and Fahimi, 2006), and sometimes, high production of $\mathrm{O}_{2}^{\bullet-}$ from a XOD system cause epidermal cell death, that cannot be prevented by plant defense system. In the present study, MAO and XOD were considerably altered under the influence of chilling stress and nutrient deprivation; the activities of both these enzymes were concomitant with the levels of ROIs in the rice seedlings (Figures 3 and 4). For instance, significantly higher levels of $\mathrm{MAO}$ and XOD under $\mathrm{N}$ - or P-deprivation, led to the greater production of ROIs under these conditions. While, comparative lower levels of MAO and XOD in K-deprived seedlings were consistent with lower accumulation of ROIs (Figures 3 and 4).
It was found that all the seed priming treatments significantly reduced the activities of $\mathrm{MAO}$ and $\mathrm{XOD}$ (Figure 4), which indicate a possible reason of reduced ROIs-accumulation and oxidative stress in primed rice seedlings.

The antioxidant defense system of plants mainly including enzymatic (SOD, POD, CAT, GPX, GR, GST etc.) and nonenzymatic (GSH, Vc, Ve etc.) antioxidants, is regarded to overcome the cascades of uncontrolled oxidation and protect the plant cells from ROIs-induced oxidative damage (Foyer and Noctor, 2005; Gill and Tuteja, 2010; Anjum et al., 2015; Chen et al., 2015). The SOD plays a key part in catalyzing the dismutation of $\mathrm{O}_{2}^{\bullet-}$, while CAT, POD, and GPX contribute in scavenging of $\mathrm{H}_{2} \mathrm{O}_{2}$ (Gill and Tuteja, 2010; Anjum et al., 2015; Fahad et al., 2015). In present study, CAT and POD were significantly enhanced with $\mathrm{N}$ - or P-deprivation, and their activities were well related with increased $\mathrm{H}_{2} \mathrm{O}_{2}$ concentration in these treatments (Figures 3 and 5). Accordingly, comparatively lower activities of these enzymes in K-deprived seedlings were concomitant with the less $\mathrm{H}_{2} \mathrm{O}_{2}$ generation (Figures 3 and 5). Increase in CAT and POD activities in $\mathrm{N}$ - or P-deprived rice seedlings is in agreement with previous studies on $\mathrm{N}$ or P-deprived mulberry (Tewari et al., 2007), N-deprived wheat (Polesskaya et al., 2004), P-deficient maize (Tewari et al., 2004), and P-deficient bean (Juszczuk et al., 2001) plants. Compared with other $\mathrm{H}_{2} \mathrm{O}_{2}$-scavenging enzymes, $\mathrm{POD}$ was highly triggered under chilling stress (Figure 5C), which indicates that this enzyme was more active under stress conditions. He et al. (2010) also reported that POD was more responsive to chilling stress than other antioxidant enzymes. In the present study, activities of GR and GST were also influenced by chilling stress and different nutrient management regimes but their responses were variable with stress conditions (Figures 5E,F). The GR activity was significantly enhanced with K-deprivation as well as chilling stress, while reduced with P-deprivation. Tewari et al. (2007) also found that K-deprivation enhanced the GR activity in mulberry leaves, while P-deprived plants recorded the lower GR activity than those with $\mathrm{N}$ - or K-deprivation. Moreover, high GR activities in rice under chilling stress have also been demonstrated by Huang and Guo (2005).

Non-enzymatic antioxidants like GSH, Vc, and Ve also play key role in stress tolerance of crop plants. The GSH and Vc are involved in many cellular processes under stress, and can directly detoxify ROIs and thus contribute to non-enzymatic ROIs-scavenging (Foyer and Noctor, 2005; Gill and Tuteja, 2010). The $\mathrm{Ve}$ is regarded to maintain the membrane stability, by quenching or scavenging ROIs like singlet oxygen. In the present study, the GSH, Vc, and Ve were reduced with $\mathrm{N}$-deprivation (Figure 6), which was consistent with high ROIs-production and poor growth performance in these treatments (Figures 1-3). Likewise, higher GSH and Vc activities were correlated with lower ROIs-production, in K-deprived seedling. Chilling stress did not affect Ve, but altered the GSH and Vc contents depending on the nutrient management regimes. Total antioxidant capability of rice seedlings was generally, regulated with nutrient deprivation as well as chilling stress (Figure 6D), which clearly indicate the occurrence of oxidative stress. Considering all the antioxidants, it was clear that although the antioxidants were generally triggered 
under stress, yet their levels were not enough to overcome the increasing level of ROIs. The disproportionate increase of ROIs-producing oxidases (e.g., MAO, XOD), in comparison to ROIs-scavenging enzymes (Figures 4-6) might be suggested to be responsible for oxidative stress, which hampered the seedling growth under sub optimal temperature and nutrient supply.

All the seed priming treatments were found to trigger or at least maintain the antioxidant defense system of rice seedlings compared with $\mathrm{NP}+\mathrm{CS}$ under all the nutrient management regimes (Figures 5 and 6). The positive role of seed priming in regulating enzymatic and non-enzymatic antioxidants has been well established under different kinds of abiotic stresses (Xu et al., 2011; Zheng et al., 2015; Hussain et al., 2016). In the present study, GR and T-AOC were significantly enhanced by $\mathrm{Se}+\mathrm{CS}$ and SA+CS compared with NP+CS; the positive effects of seed priming treatments on the other enzymatic and nonenzymatic antioxidants were rarely significant (Figures 5 and 6). Interestingly, the accumulations of ROIs were significantly lower in all the seed priming treatments (Figure 3), indicating that the reduced activities of ROIs-producing enzymes (MAO and $\mathrm{XOD}$ activities) in primed rice seedlings (Figure 4) might be the possible reason for such clear difference along with the role of scavenging antioxidants. Chen and Arora (2013) proposed that seedling emerged from primed seeds cope with environmental stresses by vigorous head-start or/and cross tolerance. During priming process, early imbibition process promotes the efficient mitochondrial development by augmenting energy metabolism, while after rehydration of primed seeds, main cellular processes such as the de-novo synthesis of nucleic acids and proteins, ATP production, activation of DNA repair and antioxidant mechanisms are triggered leading to higher stress tolerance ability. Several studies on different abiotic stresses have confirmed that enhanced antioxidant levels during priming helped rice seedlings to overcome the stress-induced challenges after germination, such as ROIs-production (Bailly et al., 2000, 2008; Khaliq et al., 2015; Zheng et al., 2015). In the present study, 18days-old seedlings were analyzed for the measurements of ROIs and antioxidants, in order to examine the effects of temperature and nutrient treatments. It can be assumed that reduced ROIsproduction and activities of $\mathrm{MAO}$ and $\mathrm{XAO}$ in primed rice seedlings, might also be the effect of strong anti-oxidative defense system during early phase of seedling growth. This assumption is also supported by our previous study on chilling stress (Hussain et al., 2016), where we found that effects of seed priming were more prominent on antioxidant activities of 10-days old rice seedlings. Due to slow growth rate of rice seedlings under chilling stress, we have to extend the harvesting time for at least $18 \mathrm{DAS}$ in the present study, in order to ensure that all the nutrients

\section{REFERENCES}

Anjum, S. A., Tanveer, M., Hussain, S., Bao, M., Wang, L., Khan, I., et al. (2015). Cadmium toxicity in Maize (Zea mays L.): consequences on antioxidative systems, reactive oxygen species and cadmium accumulation. Environ. Sci. Pollut. Res. 22, 17022-17030. doi: 10.1007/s11356-0154882-z from the grains were exhausted and the conditions were nutrientdeprived. It would be interesting to observe the response of ROIs-production and detoxification in primed and non-primed rice seedlings at different periods of time under multiple stress factors. Moreover, investigating the molecular mechanisms of priming-induced effects at transcriptomic and proteomic levels will further strengthen the concepts.

\section{CONCLUSION}

Chilling stress as well as deprivation of $\mathrm{N}$, P, or $\mathrm{K}$ severely hampered the seedling growth of rice, however, seed priming treatments, particularly Se- and SA-priming, were effective in enhancing the rice growth under stress conditions. The $\mathrm{N}$-deprivation caused the maximum reduction in shoot growth, while root growth was only decreased by P- or K-deprivation. The $\mathrm{N}$-deprivation enhanced the root length of rice, nevertheless, root fresh weight was unaffected. Rate of lipid peroxidation and as well as the production of ROIs was generally increased under stress conditions; the K-deprived seedlings recorded significantly lower production of ROIs compared with those under $\mathrm{N}$ - or P-deprived conditions. The responses of enzymatic and nonenzymatic antioxidants in rice seedlings were variable with stress condition. All the seed priming were found to trigger or at least maintain the antioxidant defense system of rice seedlings. More interestingly, the levels of ROIs were significantly reduced by seed priming treatments, which were consistent with the activities of MAO and XOD, under all studied conditions. These findings suggested that the reduced activity of ROIs-producing enzymes was also the main reason for better tolerance of primed rice seedlings, along with the role of ROIs-scavenging enzymes.

\section{AUTHOR CONTRIBUTIONS}

SH and MG initiated and designed the research, $\mathrm{SH}$ and FK performed the experiments and collected the data, SH, FK, and MG analyzed the data and wrote the manuscript. WC and LW edited the manuscript and provided guidance during experimentation.

\section{FUNDING}

We acknowledge the Special Fund for Agro-scientific Research in the Public Interest of China (Project No. 201103005 \& 201503122).

Bailly, C., Benamar, A., Corbineau, F., and Côme, D. (2000). Antioxidant systems in sunflower (Helianthus annuus L.) seeds as affected by priming. Seed Sci. Res. 10, 35-42. doi: 10.1016/j.plantsci.2011.06.003

Bailly, C., Benamar, A., Corbineau, F., and Dome, D. (1996). Changes in malondialdehyde contents and in superoxide dismutase, catalase, glutathione reductase activities in sunflower seeds related to accelerated seed aging. Physiol. Plant 97, 104-110. doi: 10.1111/j.1399-3054.1996.tb00485.x 
Bailly, C., El-Maarouf-Bouteau, H., and Corbineau, F. (2008). From intracellular signaling networks to cell death: the dual role of reactive oxygen species in seed physiology. C. R. Biol. 331, 806-814. doi: 10.1016/j.crvi.2008.07.022

Bhattachrjee, S. (2005). Reactive oxygen species and oxidative burst: roles in stress, senescence and signal transduction in plant. Curr. Sci. 89, 1113-1121.

Cadenas, E., and Davies, K. J. (2000). Mitochondrial free radical generation, oxidative stress, and aging. Free Radic. Biol. Med. 29, 222-230. doi: 10.1016/S0891-5849(00)00317-8

Cakmak, I. (1994). Activity of ascorbate-dependent H2O2-scavenging enzymes and leaf chlorosis are enhanced magnesium and potassium-deficient leaves, but not in phosphorus-deficient leaves. J. Exp. Bot. 45, 1259-1266. doi: $10.1093 / \mathrm{jxb} / 45.9 .1259$

Cakmak, I. (2005). The role of potassium in alleviating detrimental effects of abiotic stresses in plants. J. Plant Nutr. Soil Sci. 168, 521-530. doi: 10.1002/jpln.200420485

Chen, K., and Arora, R. (2013). Priming memory invokes seed stress-tolerance. Environ. Exp. Bot. 94, 33-45. doi: 10.1016/j.jprot.2013.08.010

Chen, W., Guo, C., Hussain, S., Zhu, B., Deng, F., Xue, Y., et al. (2015). Role of xylo-oligosaccharides in protection against salinity-induced adversities in Chinese cabbage. Environ. Sci. Pollut. Res. 23, 1254-1264. doi: 10.1007/s11356015-5361-2

Chevalier, F., and Rossignol, M. (2011). Proteomic analysis of Arabidopsis thaliana ecotypes with contrasted root architecture in response to phosphate deficiency. J. Plant Physiol. 168, 1885-1890. doi: 10.1016/j.jplph.2011.05.024

De Groot, C. C., Marcelis, L. F., Boogaard, R., Kaiser, W. M., and Lambers, H. (2003). Interaction of nitrogen and phosphorus nutrition in determining growth. Plant Soil 248, 257-268. doi: 10.1023/A:1022323215010

Deng, G., Liu, L. J., Zhong, X. Y., Lao, C. Y., Wang, H. Y., Wang, B., et al. (2014). Comparative proteome analysis of the response of ramie under N. P and $\mathrm{K}$ deficiency. Planta 239, 1175-1186. doi: 10.1007/s00425-014-2040-3

Epstein, E., and Bloom, A. J. (2005). Mineral Nutrition of Plants: Principles and Perspectives, 2nd Edn. Sunderland, MA: Sinauer Associates, Inc.

Fahad, S., Hussain, S., Saud, S., Khan, F., Hassan, S., Amanullah, et al. (2015). Exogenously applied plant growth regulators affect heat-stressed rice pollens. J. Agron. Crop Sci. 202, 139-150. doi: 10.1111/jac. 12148

Foyer, C. H., and Noctor, G. (2003). Redox sensing and signalling associated with reactive oxygen in chloroplasts, peroxisomes and mitochondria. Physiol. Plant. 119, 355-364. doi: 10.1034/j.1399-3054.2003.00223.x

Foyer, C. H., and Noctor, G. (2005). Oxidant and antioxidant signaling in plants: a re-evaluation of the concept of oxidative stress in a physiological context. Plant Cell Environ. 28, 1056-1071. doi: 10.1111/j.1365-3040.2005. 01327.x

Gill, S. S., and Tuteja, N. (2010). Reactive oxygen species and antioxidant machinery in abiotic stress tolerance in crop plants. Plant Physiol. Biochem. 48, 909-930. doi: 10.1016/j.plaphy.2010.08.016

Gomez, K. A., and Gomez, A. A. (1984). Statistical Procedures for Agricultural Research, 2nd Edn. (New York, NY: Wiley), 680.

Gunes, A., Inal, A., Alpaslan, M., Eraslan, F., Bagci, E. G., and Cicek, N. (2007). Salicylic acid induced changes on some physiological parameters symptomatic for oxidative stress and mineral nutrition in maize (Zea mays L.) grown under salinity. J. Plant Physiol. 164, 728-736. doi: 10.1016/j.jplph.2005.12.009

Hafsi, C., Romero-Puertas, M. C., del Río, L. A., Abdelly, C., and Sandalio, L. M. (2011). Antioxidative response of Hordeum maritimum L. to potassium deficiency. Acta Physiol. Plant. 33, 193-202. doi: 10.1007/s11738-010-0537-3

He, Y., Xiao, H., Wang, H., Chen, Y., and Yu, M. (2010). Effect of silicon on chilling-induced changes of solutes, antioxidants, and membrane stability in seashore paspalum turfgrass. Acta Physiol. Plant. 32, 487-494. doi: 10.1007/s11738-009-0425-x

Hodges, D. M., Andrews, C. J., Johnson, D. A., and Hamilton, R. I. (1997). Antioxidant enzyme responses to chilling stress in differentially sensitive inbred maize lines. J. Exp. Bot. 48, 1105-1113. doi: 10.1093/jxb/48.5.1105

Huang, M., and Guo, Z. (2005). Responses of antioxidative system to chilling stress in two rice cultivars differing in sensitivity. Biol. Plant. 9, 81-84. doi: 10.1007/s00000-005-1084-3

Hussain, S., Khan, F., Hussain, H. A., and Nie, L. (2016). Physiological and biochemical mechanisms of seed priming-induced chilling tolerance in rice cultivars. Front. Plant Sci. 7:116. doi: 10.3389/fpls.2016.00116
Hussain, S., Zheng, M., Khan, F., Khaliq, A., Fahad, S., Peng, S., et al. (2015). Benefits of rice seed priming are offset permanently by prolonged storage and the storage conditions. Sci. Rep. 5:8101. doi: 10.1038/srep08101

Jisha, K. C., Vijayakumari, K., and Puthur, J. T. (2013). Seed priming for abiotic stress tolerance: an overview. Acta Physiol. Plant 35, 1381-1396. doi: 10.1007/s11738-012-1186-5

Juszczuk, I., Malusà, E., and Rychter, A. M. (2001). Oxidative stress during phosphate deficiency in roots of bean plants (Phaseolus vulgaris L.). J. Plant Physiol. 158, 1299-1305. doi: 10.1078/0176-1617-00541

Kandlbinder, A., Finkemeier, I., Wormuth, D., Hanitzsch, M., and Dietz, K. J. (2004). The antioxidant status of photosynthesizing leaves under nutrient deficiency: redox regulation, gene expression and antioxidant activity in Arabidopsis thaliana. Physiol. Plant 120, 63-73. doi: 10.1111/j.00319317.2004.0272.x

Kang, H. M., and Saltveit, M. E. (2002). Chilling tolerance of maize, cucumber and rice seedling leaves and roots are differentially affected by salicylic acid. Physiol. Plant. 115, 571-576. doi: 10.1034/j.1399-3054.2002.1150411.x

Khaliq, A., Aslam, F., Matloob, A., Hussain, S., Geng, M., Wahid, A., et al. (2015). Seed priming with selenium: consequences for emergence, seedling growth, and biochemical attributes of rice. Biol. Trace Elem. Res. 166, 236-244. doi: 10.1007/s12011-015-0260-4

Kováčik, J., Klejdus, B., Babula, P., and Jarošová, M. (2014). Variation of antioxidants and secondary metabolites in nitrogen-deficient barley plants. J. Plant Physiol. 171, 260-268. doi: 10.1016/j.jplph.2013.08.004

Law, D. R., Crafts-Brandner, S. J., and Salvucci, M. E. (2001). Heat stress induces the synthesis of a new form of ribulose-1, 5-bisphosphate carboxylase/oxygenase activase in cotton leaves. Planta 214, 117-125. doi: 10.1007/s004250100592

Liu, H., Hussain, S., Zheng, M., Peng, S., Huang, J., Cui, K., et al. (2015). Dry directseeded rice as an alternative to transplanted-flooded rice in central China. Agron. Sustain. Dev. 35, 285-294. doi: 10.1007/s13593-014-0239-0

Malusà, E., Laurenti, E., Juszczuk, I., Ferrari, R. P., and Rychter, A. M. (2002). Free radical production in roots of Phaseolus vulgaris subjected to phosphate deficiency stress. Plant Physiol. Biochem. 40, 963-967. doi: 10.1016/S09819428(02)01459-6

Marschner, H. (1986). Mineral Nutrition of Higher Plants. London: Academic Press. Mittler, R. (2002). Oxidative stress, antioxidants and stress tolerance. Trends Plant Sci. 7, 405-410. doi: 10.1016/S1360-1385(02)02312-9

Paparella, S., Arau'jo, S. S., Rossi, G., Wijayasinghe, M., Carbonera, D., and Balestrazzi, A. (2015). Seed priming: state of the art and new perspectives. Plant Cell Rep. 34, 1281-1293. doi: 10.1007/s00299-015-1784-y

Patterson, B. D., MacRae, E. A., and Ferguson, I. B. (1984). Estimation of hydrogen peroxide in plant extracts using titanium (IV). Anal. Biochem. 139, 487-492. doi: 10.1016/0003-2697(84)90039-3

Polesskaya, O. G., Kashirina, E. I., and Alekhina, N. D. (2004). Changes in the activity of antioxidant enzymes in wheat leaves and roots as a function of nitrogen source and supply. Russian J. Plant Physiol. 51, 615-620. doi: 10.1023/B:RUPP.0000040746.66725.77

Ruelland, E., Vaultier, M. N., Zachowski, A., and Hurry, V. (2009). Cold signalling and cold acclimation in plants. Adv. Bot. Res. 49, 35-50. doi: 10.1016/S00652296(08)00602-2

Scheible, W. R., Morcuende, R., Czechowski, T., Fritz, C., Osuna, D., PalaciosRojas, N., et al. (2004). Genome-wide reprogramming of primary and secondary metabolism, protein synthesis, cellular growth processes, and the regulatory infrastructure of Arabidopsis in response to nitrogen. Plant Physiol. 136, 24832499. doi: $10.1104 /$ pp.104.047019

Schrader, M., and Fahimi, H. D. (2006). Peroxisomes and oxidative stress. Biochim. Biophys. Acta 1763, 1755-1766. doi: 10.1016/j.bbamcr.2006.09.006

Shin, R., and Schachtman, D. P. (2004). Hydrogen peroxide mediates plant root cell response to nutrient deprivation. Proc. Natl. Acad. Sci. U.S.A. 101, 8827-8832. doi: 10.1073/pnas.0401707101

Taka, T. (2004). The relationship of antioxidant enzymes and some physiological parameters in maize during chilling. Plant Soil Environ. 50, 27-32.

Taylor, N. L., Day, D. A., and Millar, A. H. (2002). Environmental stress causes oxidative damage to plant mitochondria leading to inhibition of glycine decarboxylase. J. Biol. Chem. 277, 42663-42668. doi: 10.1074/jbc.M204761200

Tewari, R. K., Kumar, P., and Sharma, P. N. (2007). Oxidative stress and antioxidant responses in young leaves of mulberry plants grown under nitrogen, 
phosphorus or potassium deficiency. J. Integr. Plant Biol. 49, 313-322. doi: 10.1111/j.1744-7909.2007.00358.x

Tewari, R. K., Kumar, P., Tewari, N., Srivastava, S., and Sharma, P. N. (2004). Macronutrient deficiencies and differential antioxidant responses-influence on the activity and expression of superoxide dismutase in maize. Plant Sci. 166, 687-694. doi: 10.1016/j.plantsci.2003.11.004

Wang, W., Chen, Q., Hussain, S., Mei, J., Dong, H., Peng, S., et al. (2016). Presowing seed treatments in direct-seeded early rice: consequences for emergence, seedling growth and associated metabolic events under chilling stress. Sci. Rep. 6:19637. doi: 10.1038/srep19637

Xu, S., Hu, J., Li, Y., Ma, W., Zheng, Y., and Zhu, S. (2011). Chilling tolerance in Nicotiana tabacum induced by seed priming with putrescine. Plant Growth Regul. 63, 279-290. doi: 10.1007/s10725-010-9528-z

Yoshida, S. (1981). Fundamentals in Rice Crop Science. (Los Banos: International Rice Research Institute), 269.

Yoshida, S., Forno, D. A., Cook, J. H., and Gomez, K. A. (1976). Laboratory Manual for Physiological Studies of Rice, 3rd Edn. Los Baños: International Rice Research Institute.
Zheng, L., Huang, F., Narsai, R., Wu, J., Giraud, E., He, F., et al. (2009). Physiological and transcriptome analysis of iron and phosphorus interaction in rice seedlings. Plant Physiol. 151, 262-274. doi: 10.1104/pp.109.141051

Zheng, M., Tao, Y., Hussain, S., Jiang, Q., Peng, S., Huang, J., et al. (2015). Seed priming in dry direct-seeded rice: consequences for emergence, seedling growth and associated metabolic events under drought stress. Plant Growth Regul. 78, 167-178. doi: 10.1038/srep19637

Conflict of Interest Statement: The authors declare that the research was conducted in the absence of any commercial or financial relationships that could be construed as a potential conflict of interest.

Copyright (c) 2016 Hussain, Khan, Cao, Wu and Geng. This is an open-access article distributed under the terms of the Creative Commons Attribution License (CC BY). The use, distribution or reproduction in other forums is permitted, provided the original author(s) or licensor are credited and that the original publication in this journal is cited, in accordance with accepted academic practice. No use, distribution or reproduction is permitted which does not comply with these terms. 